\title{
Bell’s Palsy “Laqwa”: Survey Based Study
}

\author{
Safila Naveed*, Hafiza Nimal Tasleem \\ Faculty of Pharmacy, Jinnah University for Women, Karachi, Pakistan \\ Email: safila117@yahoo.com, s safila117@gmail.com
}

Received 12 April 2014; revised 23 May 2014; accepted 13 July 2014

Copyright (C) 2014 by authors and OALib.

This work is licensed under the Creative Commons Attribution International License (CC BY).

http://creativecommons.org/licenses/by/4.0/

(c) (†) Open Access

\begin{abstract}
Bell's palsy is an acute disorder of the facial nerve in which full or partial loss of the movement on one side of face occurs. The Bell's palsy gets better without treatment in most, but not all, people. Swelling or inflammation of this nerve can also cause Bell's palsy. Physical therapies exercise, massage, laser, electrotherapy and thermotherapy used to hasten recovery. Many people who have a Bell's palsy at first think that they have a stroke. Bell's palsy is very different to a stroke and full recovery occurs in most cases. People are not aware about this disease therefore we have conduct survey regarding Bell's palsy, their sign symptoms and treatment in students of pharmacy, science and arts faculties. It is observed that out of 120 students' only $61.67 \%$ students have known about Bell's palsy. Only $26.67 \%$ know the causes, $46.67 \%$ know the sings $\&$ symptoms on behave of animals \& only $33.3 \%$ have some knowledge about treatments based mostly on home remedies. It is concluded that the knowledge of Bell's palsy in students is not enough to dial uncertain mishap pining of the disease $\&$ the must aware to the disease to treat other more better otherwise they will not cover fully to this disease.
\end{abstract}

\section{Keywords}

Bell's Palsy, Knowledge, Sign Symptoms and Treatment

Subject Areas: Virology

\section{Introduction}

Bell's palsy is a condition that suddenly affects movement of the muscles on the face. It develops usually on one side of the face. The seventh cranial nerve controlling movement if damage of this nerve results in Bell's palsy or paralysis of the face. Sometimes swelling or inflammation of cranial nerve can also cause Bell's palsy. This condition can affect people of different age but it is more common in people between the ages of 16 and 60 [1]-[4].

Bell's palsy is named after the discovery by Scottish anatomist Charles Bell, who was the first to describe this

${ }^{*}$ Corresponding author.

How to cite this paper: Naveed, S. and Tasleem, H.N. (2014) Bell's Palsy “Laqwa": Survey Based Study. Open Access Library Journal, 1: e487. http://dx.doi.org/10.4236/oalib.1100487 
condition in 1821 and then published his findings in a Royal Society paper entitled "On the Nerves: Giving an Account of some Experiments on their structure and functions they lead to New Arrangement of any System". The actual reason is not identified but in most cases it is due to a viral infection. Some patients have full recovery in 2 - 3 months. Usually treatment started with steroid tablets within 72 hours of the onset improves the chance of full recovery even further.

Anyone affected Bell's palsy and it affects men and women equally. The chances of occurrence are between the ages of 10 to 60 . The people who have diabetes and pregnant women are more likely to develop Bell's palsy. It is reported that about 1 in 70 people have a Bell's palsy in their life and $10 \%$ of cases family history may also be the cause of Bell's palsy.

Causes of Bell's palsy are thought that inflammation develops around the nerve of facial and as it passes through the skull from the brain the inflammation compresses the nerve as it passes through the skull and the nerve stops working until inflammation goes. The nerve stops working, the muscles also stop working. The virus that causes herpes simplex, herpes zoster, Respiratory illnesses (adenovirus) German measles (rubella), Mumps (mumps virus), Flu (influenza B) has been linked to Bell's palsy.

Signs and Symptoms of Bell's palsy appear following an ear infection, cold, eye infection. The symptoms appear rapidly and might notice them on waking eating or drinking. Bell's palsy is marked by one side droopy appearance and the inability to open/close eyes on the affected side. In rare cases it may affect both sides of face [5]-[7].

\section{Medication}

Normally drugs of choice for Bell's palsy corticosteroid used which reduce inflammation, antiviral medication if virus is cause and pain medication ibuprofen or acetaminophen for mild pain are used. Vitamin B-12 and B-6 are B-complex vitamins are important for preventing Bell's palsy. Physical therapies can and exercise facial muscles helpful for prevent this from occurring and plastic surgery may be needed to correct lasting facial nerve problems. Good nutrition and rest helpful for body as it heals. In some cases Bell's palsy is a "one-off" and about 1 in 10 people have a Bell's palsy can have a further episode in the future happen often several years afterwards and no ways to prevent the development of this disease.

\section{Methodology}

Questions regarding the bells palsy, causes, sign and symptoms physical examination, tests, happening again and precautions were asked. This data was collected by Pharmacy, science and arts faculties students at different universities of Karachi. The survey proceeded for two weeks. 120 forms were duly filled by students. Our study was not experimental and therefore no need to approach ethics committee for review before conducting the study. All the data were analysed in SPSS version 19. The questions asked from students are given below.

1) What is Bell's palsy?

2) Do you know the causes of Bell's palsy?

3) What are the signs and symptoms?

4) What are the treatments for Bell's palsy?

5) What do you think, will it happen again?

6) What are the precautions of while having Bell's palsy?

\section{Result and Discussion}

It is observed that out of 120 students' only $61.67 \%$ students have known about Bell's palsy. Only $26.67 \%$ know the causes, $46.67 \%$ know the sings \& symptoms on behave of animals \& only $33.3 \%$ have some knowledge about treatments based mostly on home remedies.

44.167\% students have an opinion that it will happen again \& only $26.67 \%$ have some knowledge about precautions. The overall survey is based on the knowledge of degree students about a disease called Bell's palsy. Most of the students are not familiar with the term "Bell's palsy" instate they are familiar with the term "Laqwa". The overall data is divided into four categories that include: Faculty of Pharmacy, Faculty of English, Faculty of Biochemistry and Faculty of Zoology.

The Biochemistry \& English students are more familiar with the disease instate of Pharmacy \& Zoology students but Pharmacy students have more knowledge about causes of Bell's palsy. Students also have knowledge 
about signs \& Symptom but have very little knowledge about medical treatments. Instate they are more familiar with home remedies. Most of the students have an opinion that the disease will not happen again in the future \& some have an opinion that the patient will not cover fully by the disease. A large criteria is unaware with the precautions which result that the patient will not cover fully. By using SPSS software we have analyze the data in different departments using different questions regarding Bell's palsy for the term of Bell's palsy we have got df 3 with p value 0.021 and for causes, sign symptoms, treatment, happening and precautions we found non significant results that indicates the awareness regarding the disease is not enough. Results are given in Table 1 and Figures 1-6. We have done this types of survey for awareness and these are very useful in form of research papers if paharmacy and medical students read these papers they will get knowledge [8]-[13].

Table 1. Awareness about Bell’s palsy with chi-square.

\begin{tabular}{lccc}
\hline & Value & df & Asymp. Sig. (2-sided) \\
\hline What is Bell's palsy & $9.730^{\mathrm{a}}$ & 3 & 0.021 \\
Do you know the causes of Bell's palsy & $7.159^{\mathrm{a}}$ & 3 & 0.067 \\
What are the signs and symptoms & $4.018^{\mathrm{a}}$ & 3 & 0.260 \\
What are the treatments for Bell's palsy & $5.400^{\mathrm{a}}$ & 3 & 0.145 \\
What do you think, will it happen again & $6.590^{\mathrm{a}}$ & 3 & 0.086 \\
What are the precautions of while having Bell's palsy & $4.432^{\mathrm{a}}$ & 3 & 0.218 \\
\hline
\end{tabular}

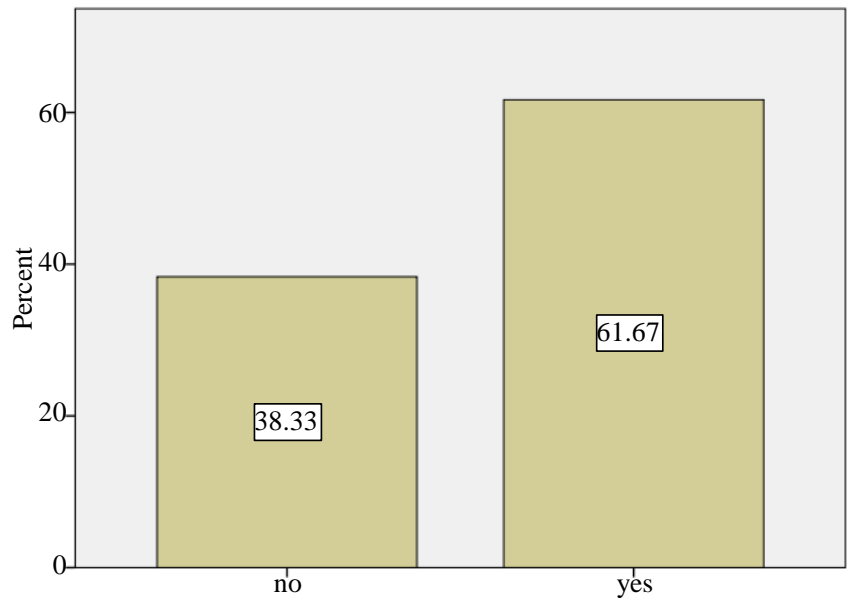

Figure 1. Knowledge about Bell’s palsy.

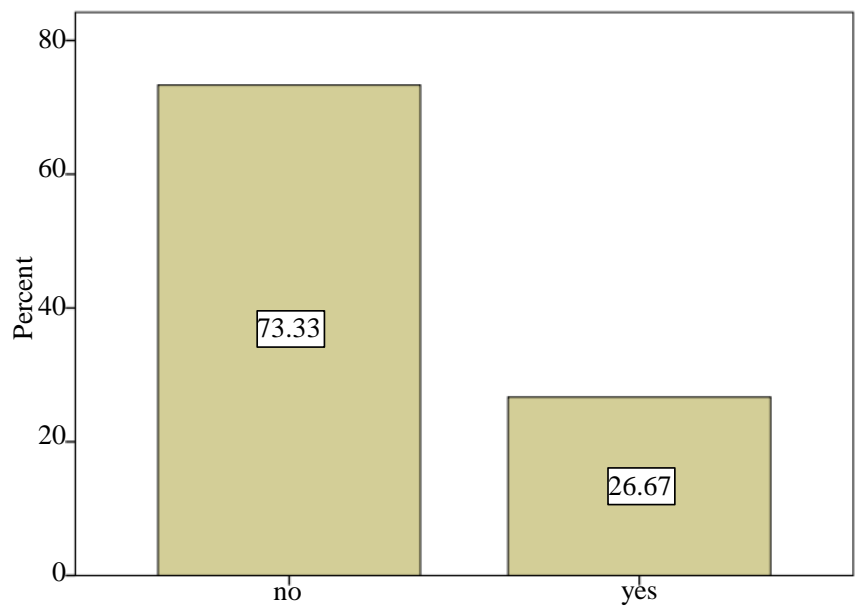

Figure 2. Knowledge about causes of Bell's palsy. 


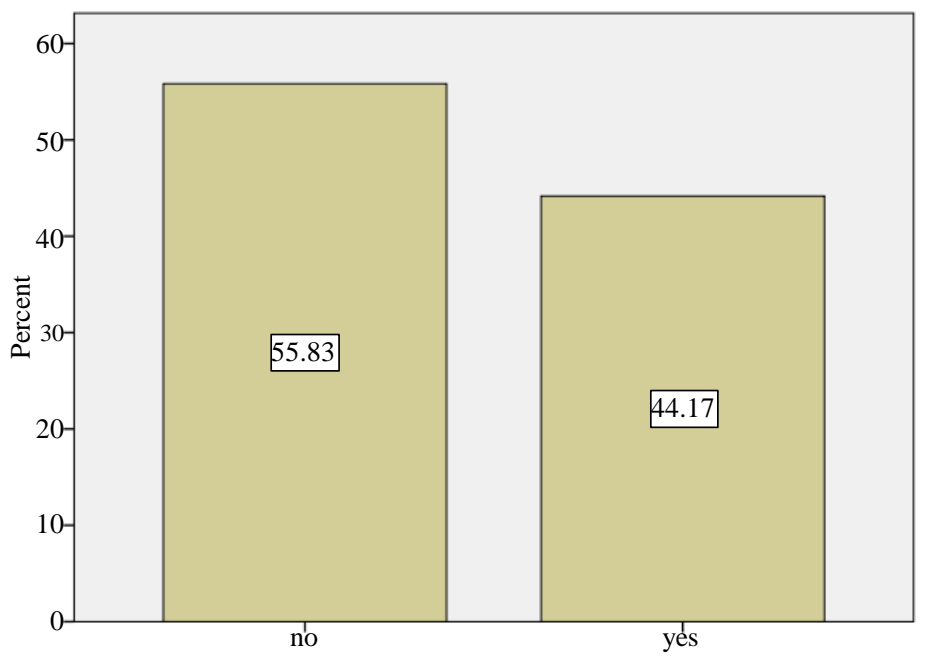

Figure 3. Knowledge about happening of Bell’s palsy.

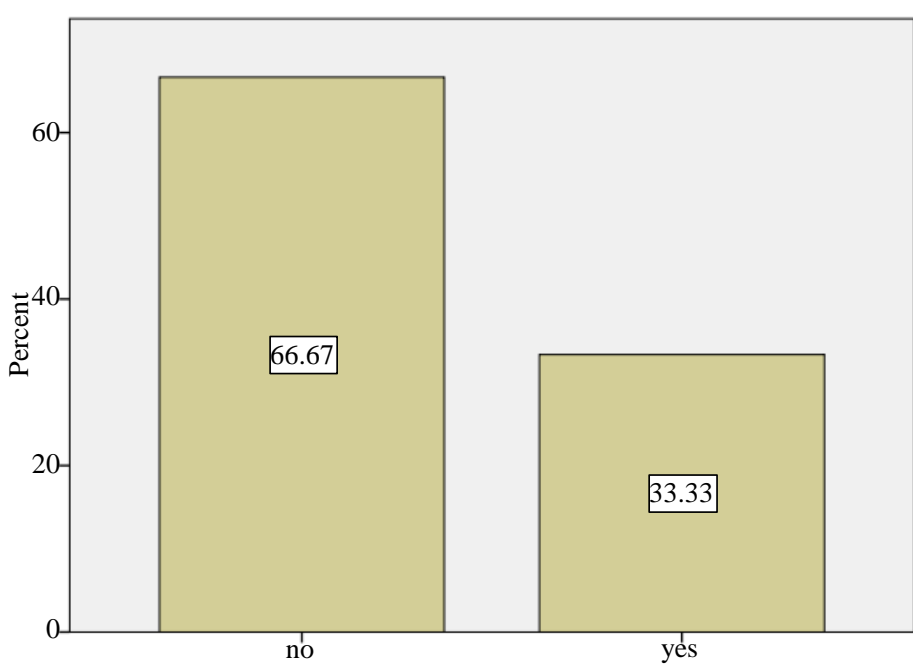

Figure 4. Knowledge about treatment of Bell's palsy.

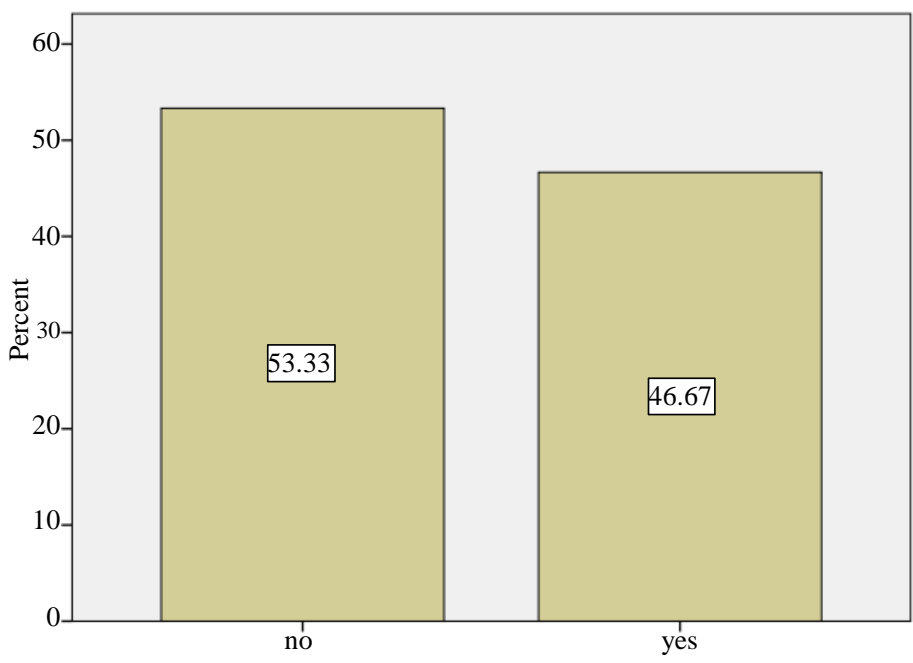

Figure 5. Knowledge about sign and sympotoms of Bell's palsy. 


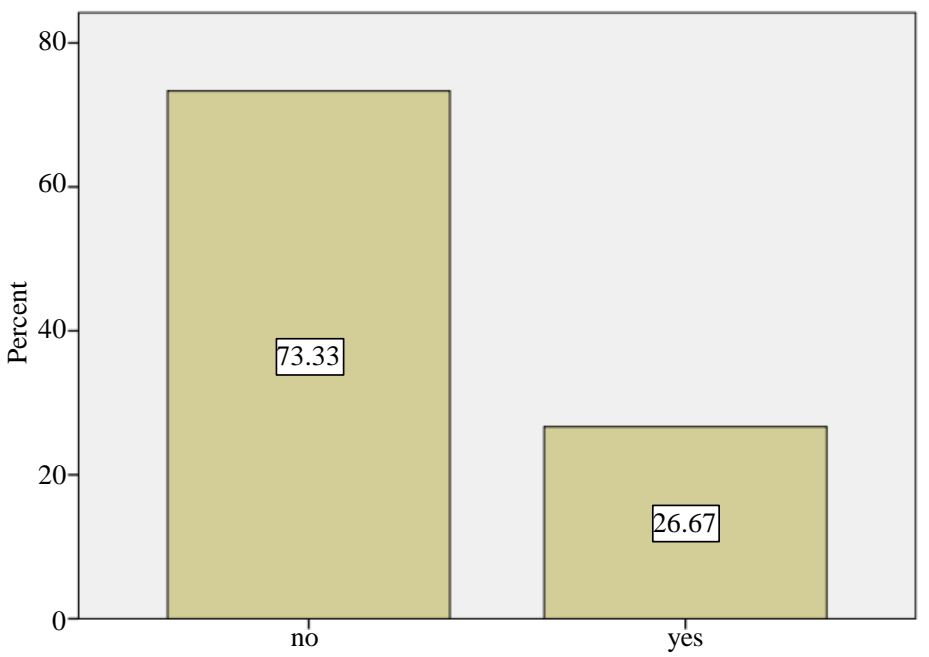

Figure 6. Knowledge about precautions of Bell’s palsy.

\section{Conclusion}

It is concluded that the knowledge of Bell's palsy in students is not enough to dial uncertain mishap pining of the disease \& the must aware to the disease to treat other more better otherwise they will not cover fully to this disease.

\section{References}

[1] Tiemstra, J.D. and Khatkhate, N. (2007) Bell’s Palsy: Diagnosis and Management. American Family Physician, 76, 997-1002.

[2] Bell’s Palsy. http://www.ninds.nih.gov/disorders/bells/bells.htm .

[3] Gilden, D.H. (2004) Clinical Practice. Bell’s Palsy. The New England Journal of Medicine, 351, 1323-1331. http://dx.doi.org/10.1056/NEJMcp041120

[4] Morris, A.M., Deeks, S.L., Hill, M.D., Midroni, G., Goldstein, W.C., Mazzulli, T., et al. (2002) Annualized Incidence and Spectrum of Illness from an Outbreak Investigation of Bell's Palsy. Neuroepidemiology, 21, 255-261. http://dx.doi.org/10.1159/000065645

[5] Peitersen, E. (2002) Bell's Palsy: The Spontaneous Course of 2500 Peripheral Facial Nerve Palsies of Different Etiologies. Acta Oto-laryngologica, 549, 4-30. http://dx.doi.org/10.1080/000164802760370736

[6] Bokhari, Z. and Zahid, S. (2006) The Role of Acupuncture in Arthritis of the Knee Joint in Addition to Local Steroid Injection. Journal of Postgraduate Medical Institute, 20, 36-39.

[7] Bokhari, Z. and Zahid, S. (2007) Pain Management in Lumbago: Role of Acupuncture in Addition to Local Steroid Infiltration at Trigger Points. Journal of Postgraduate Medical Institute, 21, 141-145.

[8] Naveed, S., Dilshad, H., Hashmi, F., Khan, A. and Salahuddin, N. (2014) Awareness about Thalassemia: A Survey Report. MJPMS Mintage Journal of Medical and Pharmaceutical \& Medical Sciences, 3, 18-19.

[9] Naveed, S., Qamar, F., Zainab, S. and Sarwer, G. (2014) A Survey Study on Awareness of Hepatitis C in Different Groups. World Journal of Pharmaceutical Sciences, 2, 449-454.

[10] Naveed, S., Rehman, N., Rehman, S., Malick, S., Yousuf, S., Marium, S., Khan, S., Ali, R. and Akhter, A. (2014) Knowledge and Attitude about Crimean Congo Hemorrhagic Fever (CCHF) amongst Local Residents of Karachi, PAKISTAN Accepted. Journal of Applied Pharmacy, 6, 166-170.

[11] Naveed, S., Ghayas, S., Wasi, H.K., Azam, M., Siddiqui, H., Talib, A., Sheikh, A.H. and Mansoor, A. (2014) Awareness of Hepatitus B in Pharm D students: Survey Based Study. DHR International Journal of Pharmaceutical Sciences (DHR-IJPS), 5. http://www.doublehelixresearch.com

[12] Naveed, S., Waheed, N. and Ghayas, S. (2014) Awareness Regarding Blastocystosis Disease: A Neglected Zoonotic Disease. MJPMS Mintage Journal of Medical and Pharmaceutical Sciences, 3, 15-16.

[13] Khatoon, H., Naveed, S. and Shahid, K. (2014) Knowledge and Awareness among Pharmacy Students about Angina Pectoris. The Global Journal of Pharmaceutical Research, 3, 1926-1934. 